\title{
INFLUENCIA DO ENVELHECIMENTO ACELERADO NA ANATOMIA DA TESTA DE SEMENTES DE SOJA, CV. MONSOY 8400
}

\author{
MONALISA ALVES DINIZ DA SILVA²; ROBERVAL DAITON VIEIRA ${ }^{3} ;$ JAIME MAIA DOS SANTOS $^{4}$
}

\begin{abstract}
RESUMO - Durante o processo de envelhecimento, as sementes sofrem alterações degenerativas que influenciam o seu potencial fisiológico. Entre estas alterações podem estar as modificações anatômicas nas camadas celulares da testa da semente. Objetivou-se, com este trabalho, verificar a relação entre a anatomia da testa de sementes de soja, cultivar Monsoy 8400 e a germinação, após o envelhecimento acelerado, pelo fato da testa apresentar um papel fundamental na conservação do potencial fisiológico das sementes. As sementes foram envelhecidas a $42^{\circ} \mathrm{C}$ e $100 \%$ UR do ar por períodos de zero, 24, 48, 72 e 96 horas. Avaliaram-se os teores de água e a germinação, posteriormente à secagem, seções transversais da testa de 10 sementes de cada tratamento foram eletromicrografadas, com microscópio eletrônico de varredura,,observando-se as camadas das células paliçádicas, ampulhetas e parenquimáticas A germinação declinou com o aumento dos períodos de envelhecimento. Houve redução da espessura das camadas da testa nos períodos de 48, 72 e 96 horas deste processo. Observou-se que, principalmente, para os períodos de envelhecimento de 72 e 96 horas, que as células da camada hipodérmica apresentaram um aspecto de colapso, sendo este acentuado para o período de 96 horas. A redução da espessura das camadas sugere a ocorrência de um colapso das células que compõem tais camadas, sendo um fator causador da redução do potencial germinativo.
\end{abstract}

Termos para indexação: Glycine max; microscopia eletrônica de varredura.

\section{INFLUENCE OF ACCELERATED AGING ON TESTA ANATOMY OF SOYBEAN (CV. MONSOY 8400) SEEDS}

\begin{abstract}
During accelerated aging seeds undergo degenerative changes that influence their physiological potential (germination and vigor). These changes include anatomical modifications in the cell layers of the seed coat. This research was carried out to verify the relationship between the seed coat anatomy of soybean, cultivar Monsoy 8400 and germination after seed aging. Accelerated aging was performed at $42^{\circ} \mathrm{C}$ and $100 \% \mathrm{RH}$ for $0,24,48,72$ and 96 hours. After aging, seed water content and standard germination were determined. After aging the seeds were dried and transverse sections of 10 seed coats of each treatment were electronically micrographed, using a scanning electron microscope. The palisade, hypodermic and parenchyma cell layers were observed. The
\end{abstract}

${ }^{1}$ Submetido em 29/08/2007. Aceito para publicação em 03/06/2008. Parte da Tese de Doutorado em Agronomia (Produção e Tecnologia de Sementes) do primeiro autor apresentada a UNESP/Jaboticabal; ${ }^{2}$ Eng. Agrônoma; Pós-Doctor, monallyysa@yahoo.com.br. ${ }^{3}$ Professor Titular,
UNESP, Campus de Jaboticabal, Dep de Produção Vegetal, CEP: 14884900, Jaboticabal-SP, rdvieira@fcav.unesp.br. ${ }^{4}$ Professor Titular, UNESP, Campus de Jaboticabal, Dep de Nematologia, , CEP: 14884-900, Jaboticabal-SP, jmsantos@fcav.unesp.br. 
results were analyzed as a randomized complete block design. The germination percentage decreased as the aging period increased. After 48, 72, and 96 hours of aging, the seed coat cell layers showed reduced thickness. After 72 and 96 hours of seed aging, the hypodermic cells showed an appearance of collapse that was more evident after 96 hours. The reduction in the thickness of cell layers suggested the occurrence of cell collapse that influenced the decrease in seed germination potential.

Index terms: Glycine max; scanning electron microscopy.

\section{INTRODUÇÃO}

A deterioração é um processo que envolve complexas alterações, que interferem no potencial fisiológico da semente. A velocidade do processo de deterioração é determinada principalmente pela interação entre o genótipo, o teor de água da semente e a temperatura do ambiente (Delouche, 2002).

Antes da morte da semente, como decorrência da deterioração, ocorrem várias alterações fisiológicas, bioquímicas e genéticas, tais como: danificação cromossômica (Roberts, 1973), perda de enzimas (Woodstock, 1973), degradação do sistema respiratório (Abdul-Baki e Anderson, 1972), diminuição da produção de ATP (Anderson, 1977) e desorganização das membranas celulares (Basavarajappa et al., 1991). Além da perda da compartimentalização celular, a desintegração do sistema de membranas promove descontrole do metabolismo e das trocas de água e solutos entre as células e o meio exterior, determinando a queda da viabilidade da semente (Marcos Filho, 1999).

Conforme a sequência hipotética proposta por Delouche e Baskin (1973), o decréscimo do potencial de armazenamento é a segunda manifestação fisiológica da deterioração, após a redução da velocidade de germinação. Assim o teste de envelhecimento acelerado pode ser considerado como um dos mais sensíveis para a avaliação do vigor, dentre os disponíveis (Marcos Filho, 1999). A exposição das sementes às elevadas temperaturas e umidade relativa do ar causa deterioração das mesmas, o que contribui para o surgimento de plântulas anormais e sementes mortas no teste de germinação (McDonald et al., 1993).

Um clima tropical, como o do Brasil, caracterizado por elevadas temperaturas e a umidade relativa do ar, predispõem as sementes de soja a uma rápida deterioração durante o armazenamento. Como a soja tem se mostrado a cultura de maior geração de divisas do agronegócio brasileiro, com uma produção de aproximadamente 60 milhões de toneladas de grãos na safra de 2007/2008 (IBGE, 2008); torna-se imperioso que para continuar atendendo a esta demanda do mercado sejam produzidas sementes de elevado potencial fisiológico.

O tegumento apresenta uma função muito importante quanto à resistência das sementes a deterioração (Dassou e Kueneman, 1984). O tegumento exerce funções de proteção ao eixo embrionário e ao tecido de reserva (Carvalho e Nakagawa, 2000); além de protegê-los de ruptura celular e perda de substâncias intracelulares, durante a embebição (Duke e Kakefuda, 1981). Assim características do tegumento tais como a impermeabilidade à água, a cor e o elevado teor de lignina, podem contribuir na obtenção de sementes de soja de elevado potencial fisiológico.

O corte transversal da testa de uma semente de soja permite distinguir quatro camadas a partir da sua superfície: cutícula, epiderme (células paliçádicas ou macroesclerídeos), hipoderme (células em ampulheta, ou células pilares ou osteoesclerídeos) e células parenquimatosas (Swanson et al., 1985).

As células esclerenquimatosas, chamadas macroesclerídeos, formam a camada paliçádica, a qual aparece de forma contínua por toda a testa, com exceção da região do hilo, onde duas camadas paliçádicas podem ser observadas. Neste caso, a camada paliçádica mais interna provém do funículo, enquanto a mais externa, do integumento externo do óvulo (Esau, 1977). As células da camada paliçádica apresentam-se alongadas, com uma disposição perpendicular à superfície da testa, paredes celulares grossas e perfuradas 
na porção superior. A composição química, o arranjo e as substâncias intercelulares da camada paliçádica influenciam a absorção de água pela semente (Duangpatra, 1976).

A hipoderme constitui-se de uma camada de células uniforme, contínua em toda a testa, com exceção da região do hilo, onde está ausente. Ela é formada por células esclerenquimatosas com parede celular de espessura desuniforme, chamadas de osteoesclerídeos, com a presença de grandes espaços intercelulares, como observado por Corner (1951), em sementes de algumas leguminosas.

O parênquima lacunoso é composto de 6-8 camadas de células parenquimatosas, as quais são tangenciais à superfície da testa, possuem a parede celular fina e protoplasma ausente (Esau, 1977).

A espessura da testa de uma semente de soja varia entre 70-100 micrometros, considerando-se as quatro camadas, sendo que existe variação entre cultivares. Ressalta-se que esta característica física é constante dentro de cada cultivar e é controlada geneticamente (Caviness e Simpson, 1974).

O conhecimento das células que compõem o tegumento torna-se importante porque é através deste que a água atinge o embrião das sementes de soja, passando principalmente através da testa (Noodén et al., 1985; Chachalis e Smith, 2000); apesar de McDonald et al. (1988) considerarem que o principal caminho percorrido pela água é a região hilar.

Uma das principais causas do decréscimo do potencial fisiológico da semente é a absorção de água ainda no campo, após a maturidade fisiológica, antes da colheita (Vieira et al., 1982). Isto despertou o interesse pela utilização de sementes que possuam testa com certo grau de dureza (Hartwig e Potts, 1987), ou seja, com testa impermeável ou semipermeável à água. Substâncias impermeáveis à água tais como ceras, suberina, tanino ou lignina podem ser encontrados na parede celular (McDougall et al., 1996). A lignina é um polímero natural e está presente apenas na testa (Lewis e Yamamoto, 1990).

Tavares et al. (1987) verificaram que os maiores valores de lignina encontravam-se nas linhagens de soja com testa impermeável. Panobianco et al. (1999) e Carbonell e Krzyzanowski (1995) também verificaram variações no teor de lignina da testa entre genótipos de soja, com forte relação com a resistência ao dano mecânico. No entanto, não está devidamente esclarecido se existe ou não uma correlação entre o teor de lignina e a espessura da testa (Agrawal e Menon, 1974; Tavares et al., 1987).

Objetivou-se com este trabalho verificar a relação entre a anatomia da testa de sementes de soja, cultivar Monsoy 8400, e a germinação após o envelhecimento acelerado, pelo fato da testa apresentar um papel fundamental na conservação do potencial fisiológico das sementes.

\section{MATERIAL E MÉTODOS}

O presente trabalho foi desenvolvido nos Laboratórios de Análise de Sementes do Departamento de Produção Vegetal e de Microscopia Eletrônica de Varredura da UNESP, Campus de Jaboticabal.

Foi utilizada a cultivar de soja Monsoy 8400, safra 2001. Após a recepção, as sementes foram expurgadas, homogeneizadas, acondicionadas em embalagem porosa e armazenadas em câmara fria $\left(10^{\circ} \mathrm{C}\right)$. Para a caracterização inicial da qualidade das sementes foram realizadas as seguintes determinações: teor de água, germinação (tendo com substratos papel e areia), condutividade elétrica, emergência de plântulas em campo e teor de lignina da testa.

Teor de água: foi avaliado pelo método da estufa a $105 \pm 3^{\circ} \mathrm{C}$ durante 24 horas (ISTA, 2002). Germinação: foi realizada com quatro repetições de 50 sementes, à temperatura de $25^{\circ} \mathrm{C}$, utilizando-se como substrato rolo de papel toalha, umedecido na proporção de 2,5 vezes a massa do papel. As contagens foram feitas aos cinco e oito dias após a semeadura, computando-se a porcentagem final de plântulas emersas (ISTA, 2002). Foi avaliada também a germinação em substrato areia, semeando-se quatro repetições de 50 sementes, em caixas plásticas ( $26 \times 16$ x 8,5 cm). As sementes foram cobertas com 2 a $3 \mathrm{~cm}$ de substrato (areia fina de rio) e irrigadas com base em $70 \%$ da capacidade de retenção de água pelo substrato. As caixas foram mantidas à temperatura ambiente $\left(25^{\circ} \mathrm{C}\right.$ a $\left.30^{\circ} \mathrm{C}\right)$ por 10 dias, quando então foi realizada a contagem do número de plântulas normais. Condutividade elétrica: foi conduzida utilizando-se quatro repetições de 50 sementes. Após a pesagem, as sementes foram imersas em $75 \mathrm{~mL}$ de água deionizada e mantidas durante 24 horas, à temperatura de $25^{\circ} \mathrm{C}$. Ao término do período, a condutividade elétrica da solução foi determinada em condutivímetro DIGIMED CD-21 (Hampton e Tekrony, 1995; Vieira e Krzyzanowski, 1999). Emergência das plântulas em campo: conduzida com quatro repetições de 50 sementes. A semeadura foi realizada em campo mantido sob irrigação, em linhas de 2,0m espaçadas de 0,3m entre si. A avaliação foi realizada aos 21 dias após a semeadura (Nakagawa, 1999). Teor de lignina da testa: Foram usadas testas de 10 sementes, retiradas e secas à temperatura de $55^{\circ} \mathrm{C}$, por 48 horas. Posteriormente, as testas foram trituradas em 
moinho de bola, com o objetivo de obter um pó bastante fino. A presença de lignina foi quantificada em duas repetições de $0,5 \mathrm{~g}$ de testa, pelo método do permanganato de potássio (Van Soest e Wine, 1968).

Anatomia da testa: Para o estudo da anatomia da testa de sementes de soja envelhecidas, os tratamentos foram obtidos pela colocação das sementes, em condições semelhantes às do teste de envelhecimento acelerado (Marcos Filho, 1999), ou seja, uma camada única de sementes foi disposta sobre tela suspensa, em caixas plásticas de germinação $(11 \mathrm{~cm} \times 11 \mathrm{~cm}$ x $5 \mathrm{~cm}$ ), com $40 \mathrm{~mL}$ de água deionizada e mantidas a $42^{\circ} \mathrm{C}$ e $100 \%$ UR do ar por períodos de zero, 24, 48, 72 e 96 horas. Ao término dos períodos de envelhecimento, foi avaliado o teor de água das sementes pelo método da estufa (ISTA, 2002). Posteriormente, foi conduzido o teste de germinação, computando-se a porcentagem de plântulas normais aos cinco dias após a semeadura. As sementes que não foram utilizadas nos testes de teor de água e de germinação passaram pelo processo de secagem em estufa com circulação de ar forçado, à $28^{\circ} \mathrm{C}$, até que atingissem teores de água entre $9-11 \%$, antes da realização das eletromicrografias, no microscópio eletrônico de varredura, marca JEOL, modelo JFM 5410.

Para a realização das eletromicrografias da testa, foram feitos cortes transversais na região mediana da semente circundando a região do hilo, com lâmina de aço, sendo que o material obtido foi metalizado com ouro paládio, sem prévia fixação e desidratação, por apresentar-se seco. Foram observadas as camadas das células paliçádicas (macroesclerídeos), ampulhetas (osteoesclerídeos) e parenquimáticas. Para cada período de envelhecimento foram eletromicrografadas 10 sementes, sendo que de cada semente foi obtido um corte da seção transversal. Para cada uma das camadas, de cada semente eletromicrografada, foram feitas cinco medições, usando paquímetro digital, registrando os valores em mm, posteriormente transformados em $\mu \mathrm{m}$.

Empregou-se o delineamento inteiramente casualizado, tanto para a germinação como para a espessura das camadas. As médias foram comparadas pelo teste de Tukey a 5\% de probabilidade. Os valores de germinação foram transformados em arc sen $\sqrt{ } \mathrm{x} / 100$.

\section{RESULTADOS E DISCUSSÃO}

Na Tabela 1 são mostrados os resultados da caracterização inicial das sementes de soja, cultivar Monsoy 8400, quanto à germinação, emergência de plântulas, condutividade elétrica e teores de água e de lignina. Verificou-se que o lote usado apresentava elevado potencial fisiológico, em virtude dos valores dos testes de germinação, emergência e condutividade elétrica. De acordo com Vieira (1994) lotes de sementes de soja com condutividade elétrica até $70-80 \mu$ mhos. $\mathrm{cm}^{-1} \mathrm{~g}^{-1}$ têm sido considerados como de alto vigor . O teor de lignina acima de 5\% mostrou que o genótipo utilizado apresentava boa resistência ao dano mecânico, conforme considerações de Alvarez et al. (1997).

\section{TABELA 1. Potencial fisiológico e teores de água e de lignina iniciais de sementes de soja, cultivar Monsoy 8400.}

\begin{tabular}{lc}
\hline \multicolumn{1}{c}{ Determinações } & Cultivar Monsoy 8400 \\
\hline Teor de água (\%) & 9,9 \\
\hline Germinação em papel (\%) & 94,0 \\
\hline Germinação em areia (\%) & 86,5 \\
\hline $\begin{array}{l}\text { Condutividade elétrica } \\
\left(\mu \text { mhos.cm }{ }^{-1} \mathrm{~g}^{-1}\right)\end{array}$ & 59,9 \\
\hline Emergência em campo (\%) & 93,0 \\
\hline Teor de lignina da testa (\%) & 8,19 \\
\hline
\end{tabular}

Na Tabela 2 é apresentado o teor de água das sementes, logo após os períodos de envelhecimento acelerado. Verificou-se aumento à medida que se prolongou o período de envelhecimento das sementes.

A germinação das sementes de soja (Tabela 2), após ser exposta a diferentes períodos de envelhecimento acelerado, indicou, à $42^{\circ} \mathrm{C}$, que o potencial fisiológico declinou com o aumento dos períodos de envelhecimento. Nos períodos de 48, 72 e 96 horas de envelhecimento, foi verificada redução da espessura das camadas da testa das sementes de soja (Tabelas 2, Figuras 1 e 2), o mesmo não sendo observado no período de envelhecimento de 24 horas (Figura 1). A redução da espessura das camadas sugere a ocorrência de um colapso das células que compõem tais camadas, o que pode estar relacionado com a redução do potencial germinativo (Tabela 2), ao se considerar o referido colapso como um dano físico às células e, conseqüentemente, à testa.

TABELA 2. Teor de água e envelhecimento acelerado de 
sementes de soja, cv. Monsoy 8400 e espessura das camadas paliçádica, hipodérmica, parenquimática e total da testa, após diferentes períodos de envelhecimento $(\mathrm{PE}), \mathrm{a}^{\circ} \mathrm{C}$.

\begin{tabular}{ccccccc}
\hline PE & TA $^{1}$ & EA $^{1}$ & \multicolumn{5}{c}{ Espessura $(\mu \mathrm{m})$} \\
\hline (hora) & $(\%)$ & $(\%)$ & Paliçádica & hipodérmica & parenquimática & Total \\
\hline Zero & 9,9 & $86 \mathrm{a}$ & $55,00 \mathrm{a}$ & $49,81 \mathrm{a}$ & $25,65 \mathrm{ab}$ & $130,50 \mathrm{a}$ \\
\hline 24 & 21,3 & $80 \mathrm{ab}$ & $53,35 \mathrm{a}$ & $59,04 \mathrm{a}$ & $30,77 \mathrm{a}$ & $143,12 \mathrm{a}$ \\
\hline 48 & 27,0 & $76 \mathrm{ab}$ & $42,42 \mathrm{~b}$ & $26,16 \mathrm{~b}$ & $21,39 \mathrm{~b}$ & $90,00 \mathrm{~b}$ \\
\hline 72 & 31,3 & $71 \mathrm{bc}$ & $40,35 \mathrm{~b}$ & $15,04 \mathrm{bc}$ & $18,08 \mathrm{~b}$ & $73,46 \mathrm{~b}$ \\
\hline 96 & 35,0 & $56 \mathrm{c}$ & $40,62 \mathrm{~b}$ & $12,73 \mathrm{c}$ & $18,58 \mathrm{~b}$ & $71,92 \mathrm{~b}$ \\
\hline C.V.(\%) & - & 8,24 & 14,27 & 31,39 & 26,19 & 18,43 \\
\hline
\end{tabular}

Médias seguidas pela mesma letra, na coluna, não diferem entre si pelo Teste de Tukey, no nível de 5\% de probabilidade.

${ }^{1} \mathrm{TA}=$ teor de água, $\mathrm{EA}=$ envelhecimento acelerado.

FIGURA 1. Eletromicrografias de varredura da testa de quatro sementes de soja, cultivar Monsoy 8400. A e B) Sementes não envelhecidas, exibindo alteração de espessura na camada hipodérmica, em A) Camada hipodérmica de espessura menor, em B) Camada hipodérmica de espessura maior. C e D) Sementes envelhecidas por 24 e 48 horas, respectivamente, à $42^{\circ} \mathrm{C} .(a=$ camada paliçádica; $b=$ hipoderme $\mathrm{e}$; $\mathrm{c}=$ parênquima lacunoso $)$.

Entretanto, Giurizatto et al. (2003), ao avaliarem a viabilidade e o vigor de sementes de nove genótipos de soja, com diferentes
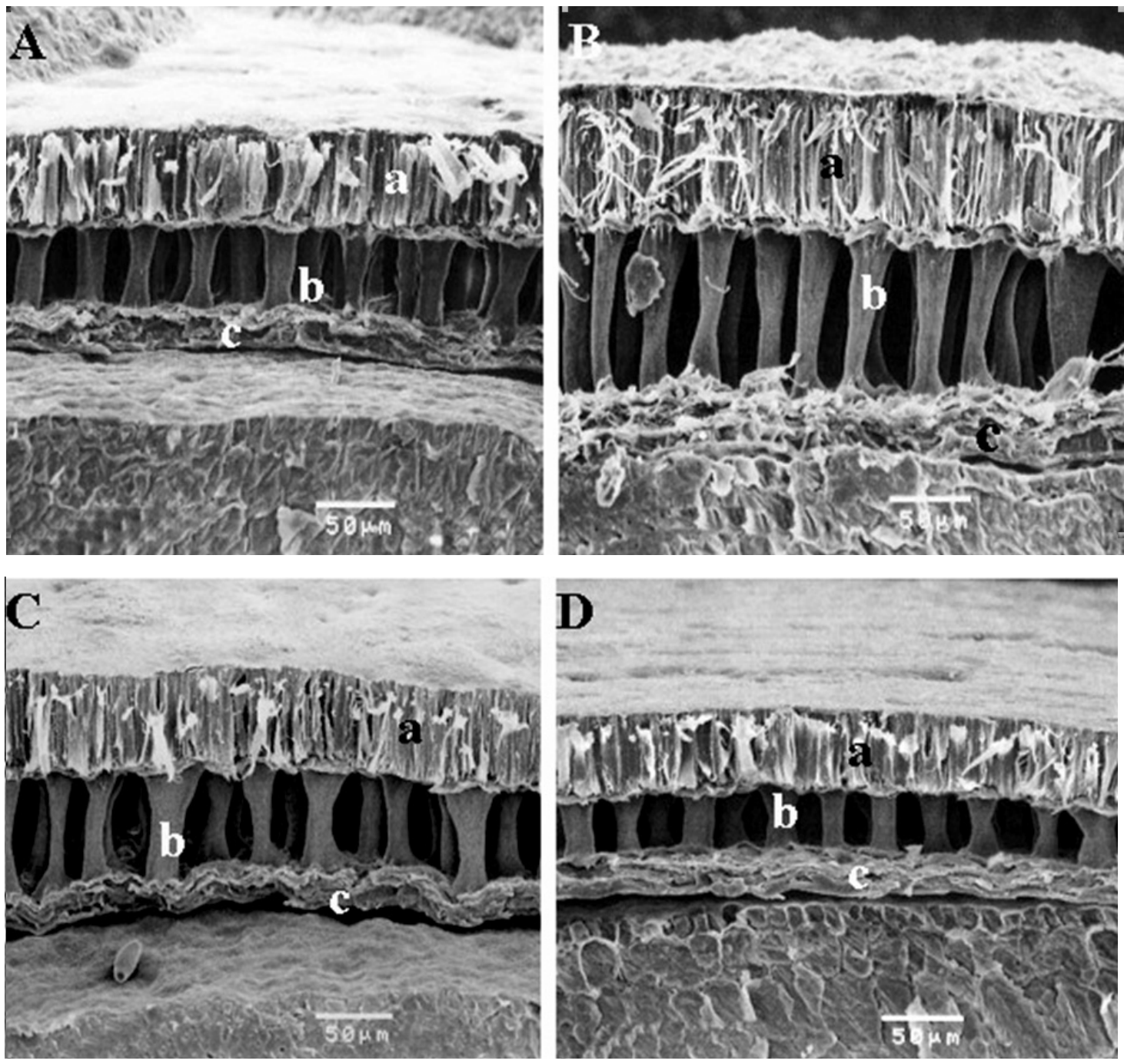
FIGURA 2. Eletromicrografias de varredura da testa de quatro sementes de soja, cultivar Monsoy 8400. A e B) Sementes envelhecidas por 72 horas, à $42^{\circ} \mathrm{C}$, exibindo pouca alteração no grau de colapso da camada hipodérmica. C e D) Sementes envelhecidas por 96 horas, à $42^{\circ} \mathrm{C}$, exibindo alteração no grau de colapso da camada hipodérmica, em C) Camada hipodérmica com reduzida espessura, em D) Camada hipodérmica quase ausente. ( $a=$ camada paliçádica; $b=$ hipoderme $e ; c=$ parênquima lacunoso).
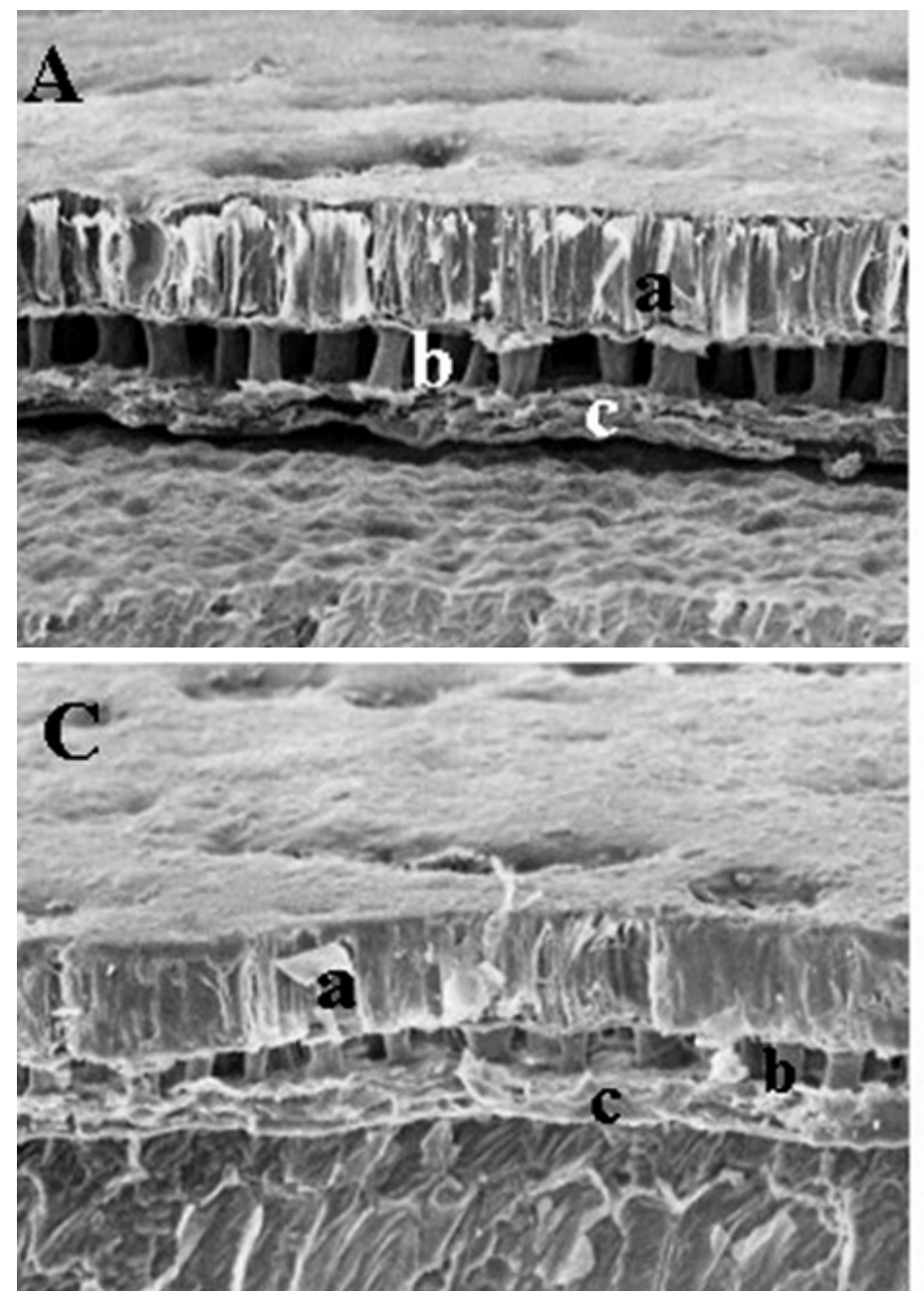

colorações e espessuras de tegumento, colhidas em duas épocas, concluíram que a espessura não é uma característica que per si assegura melhor qualidade fisiológica das sementes. Salienta-se que esses autores utilizaram metodologia própria a qual pode ter interferido na espessura do tegumento. Deve ser levado em conta que o grau de hidratação dos tecidos das sementes pode ter sofrido alterações que possam ter interferido na espessura do tegumento.

A espessura total do conjunto das camadas paliçádica, hipodérmica e parenquimática (Tabela 2) foi de 130,5 micrometros. Por sua vez, Giurizatto et al. (2003) verificaram que a espessura do tegumento de sementes de soja variou de 225 à $439 \mu \mathrm{m}$, conforme o genótipo. Tais valores podem
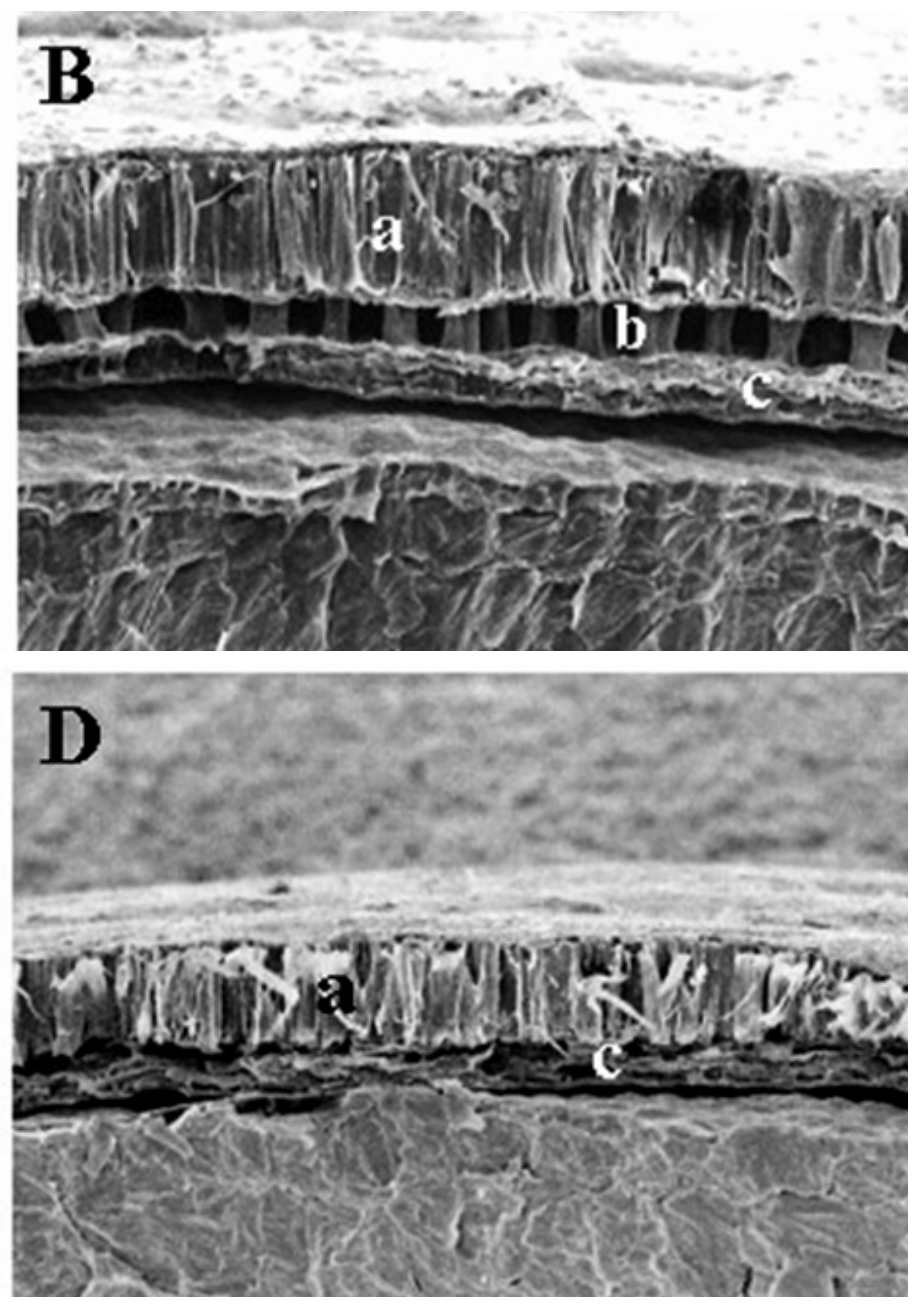

ser resultado da forma de preparo do tegumento para a visualização de sua espessura. De acordo com Yaklich et al. (1994), alterações no grau de hidratação dos tecidos da semente poderiam afetar sua morfologia e citologia.

As eletromicrografias de varredura de cortes transversais da testa das sementes na figura 1 mostram as células estruturais da testa. Podem ser observadas três camadas de células visíveis. As células de aparência colunar são as células paliçádicas. Não foram verificados espaços entre as células nessa camada. A espessura média da camada de células paliçádicas, mensurada em 10 sementes não envelhecidas foi próximo de $55 \mu \mathrm{m}$. A camada hipodérmica, que contém células em ampulheta ou osteoesclerídeos, é mais fina do que 
a camada paliçádica; assim, a espessura média dessa camada foi de $49,81 \mu \mathrm{m}$. Os cortes das sementes, como indicado pelas eletromicrografias de varredura, apresentaram estruturas altamente organizadas na testa. $\mathrm{O}$ mesmo pode ser verificado em sementes de outras leguminosas (Sefa-Dedeh e Stanley, 1979; Agbo et al., 1987). Abaixo dos osteoesclerídeos estão as células do parênquima lacunoso, as quais formam uma camada celular amorfa.

O critério de seleção para a escolha das eletromicrografias em cada figura baseou-se na escolha de cortes da testa que representassem o que ocorreu nas 10 sementes avaliadas por tratamento, em termos de alteração na espessura da camada hipodérmica. Pôde-se observar que, principalmente para os períodos de envelhecimento de 72 e 96 horas (Figura 2), as células da camada hipodérmica apresentaram aspecto de colapso, sendo este acentuado para o período de 96 horas.

A alteração anatômica da camada hipodérmica das sementes envelhecidas pode de alguma forma, estar relacionada com a redução do potencial fisiológico (Tabela 2), pois o colapso das células da hipoderme pode ser visto como um dano físico na testa.

Alguns pesquisadores (Simon e Raja Harun, 1972; McKersie e Stinson, 1980; Bewley e Black, 1994; Hampton e Tekrony, 1995) consideram que, na fase inicial do processo de embebição, a capacidade da semente de reorganizar suas membranas, assim como de reparar certos danos físicos e/ou biológicos pode influenciar de modo acentuado a quantidade de lixiviados por ela liberados. A habilidade das sementes de repararem os danos físicos e/ou biológicos, na fase inicial do processo de embebição, talvez interfira no potencial de germinação das sementes.

\section{CONCLUSÕES}

O envelhecimento provocado às sementes pela sua exposição a elevadas temperaturas e umidade relativa, causa alterações anatômicas na camada hipodérmica na testa de sementes de soja, que estão associadas com a perda do poder germinativo.

\section{REFERÊNCIAS}

ABDUL-BAKI, A.A.; ANDERSON, J.D. Physiological and biochemical deterioration of seeds. In: KOZLOWSKI, T.T.
(Ed.). Seed biological. New York: Academic Press, 1972. v.2, cap,4, p.283-315.

AGBO, G.N.; HOSFIELD, M.A.; UEBERSAX, M.A.; KLOMPARENS, K. Seed microstructure and its relationship to water in isogenic lines and a cultivar of dry beans (Phaseolus vulgaris L.). Food Microstructure, Chicago, v,6, p.91-102, 1987.

AGRAWAL, K.; MENON, K. Lignin content and seed coat thickness in relation to seedcoat cracking in soybean. Seed Research, New Delhi, v.2, p.64-66. 1974.

ALVAREZ, P.J.C.; KRZYZANOWSKI, F.C.; MANDARINO, J. M.; FRANÇA NETO, J.B. Relationship between soybean seed coat lignin content and resistance to mechanical damage. Seed Science and Technology, Zurich, v.25, n.2, p.209-214, 1997.

ANDERSON, J.D. Adenylate metabolism of embryonic axes from deteriorated soybean seeds. Plant Physiology, Lancaster, v.59, p.610-614, 1977.

BASAVARAJAPPA, B.S.; SHETTY, H.S.; PRAKASH, H.S. Membrane deterioration and other biochemical changes, associated with accelarated ageing of maize seeds. Seed Science and Technology, Zurich, v.19, n.2, p.279-286, 1991.

BEWLEY, J.D.; BLACK, M. Seeds: physiology of development and germination. New York: Plenum Press, 1994. 444p.

CARBONELL, S.A.M.; KRZYZANOWSKI, F.C. The pendulum test for screening soybean genotypes for seeds resistant to mechanical damage. Seed Science and Technology, Zurich, v.23, n.2, p.331-339, 1995.

CARVALHO, N.M.; NAKAGAWA, J. Sementes: ciência, tecnologia e produção. 4.ed. Jaboticabal: FUNEP, 2000. 588p.

CAVINESS, C.E.; SIMPSON, A.M.JR. Influence of variety and location on seed coat thickness of mature soybean seed. Proceedings of the Association of Official Seed Analysts, Lansing, v.64, p.102-108, 1974.

CHACHALIS, D.; SMITH, M.L. Imbibition behavior of soybean (Glycine max L. Merrill) accessions with different testa characteristics. Seed Science and Technology, Zurich, v.28, p.321-331, 2000.

CORNER, E.J. The leguminous seed. Phytomorphology, St. Paul, v.1, p.117-150, 1951.

DASSOU,S.; KUENEMAN, E. A. Screening methodology for resistance to field weathering of soybean seed. Crop Science, Madison, v.24, p.774-779, 1984. 
DELOUCHE, J.C. Germinação, deterioração e vigor da semente. Seed News, Pelotas, n.6, p.24-31, 2002.

DELOUCHE, J.C.; BASKIN, C.C. Accelerated aging techniques for predicting the relative storability of seed lots. Seed Science and Technology, Zurich, v.1, n.2, p.427-452, 1973.

DUANGPATRA, J.J. Some characteristics of the impermeable seed coat in soybean (Glycine max (L.) Merrill). 1976. 91f. Dissertation (Ph.D) - Mississipi State University, Mississipi.

DUKE, S.H.; KAKEFUDA, G. Role of the testa in preventing cellular rupture during imbibition of the legume seeds. Plant Physiology, Bethesda, v.67, n.2, p.449-456, 1981.

ESAU, K. Anatomy of seeds plants. New York: John Wiley and Sons, 1977. 550p.

GIURIZATTO, M.I.K.; SOUZA, L.C.F.; ROBAINA, A.D.; GONÇALVES, M.C. Efeito da época de colheita e da espessura do tegumento sobre a viabilidade e o vigor de sementes de soja. Ciência e Agrotecnologia, Lavras, v.27, n.4, p.771-779, 2003.

HAMPTON, J.G.; TEKRONY, D.M. Handbook of vigour test methods. 3.ed. Zurich: ISTA, 1995. p.22-34.

HARTWIG, E.E.; POTTS, H.C. Development and evaluation of impermeable seed coats for preserving soybean seed quality. Crop Science, Madison, v.27, n.3, p.506-508, 1987.

INSTITUTO BRASILEIRO DE GEOGRAFIA E ESTATÍSTICA. Disponível em: <http://www.ibge.gov.br>. Acesso em: 01 jun. 2008.

INTERNATIONAL SEED TESTING ASSOCIATION. Handbook of vigour test methods. 3. ed. Zurich: ISTA, 2002. 117p.

LEWIS, N.G.; YAMAMOTO, E. Lignin: occurrence, biogenesis and biodegradation. Annual Review of Plant Physiology Plant Molecular Biology, Palo Alto, v.41, p.455-496, 1990.

MARCOS FILHO, J. Teste de envelhecimento acelerado. In: KRZYZANOWSKI, F.; VIEIRA, R.D.; FRANÇA-NETO, J.B. (Ed.). Vigor de sementes: conceitos e testes. Londrina: ABRATES, 1999. cap.3, p.1-24.

MCDONALD, M.B.; GUPTA, I.J.; SCHMITTHENNER, A. F. Effect of storage fungi on seed vigour of soybean. Seed Science and Technology, Zurich, v.21, p.581-591, 1993.

MCDONALD, M.B.; VERTUCCI, C.W.; ROOS, E.C. Soybean seed imbibition: water absorption by seed parts.
Crop Science, Madison, v.28, p.993-997, 1988.

McDOUGALL, G.J.; MORRISON, I.M.; STEWART, D.; HILLMAN, J.R. Plant cell walls as dietary fibre: range, structure, processing and function. Journal of the Science of Food and Agriculture, Chichester, v.70, n.2, p.133-150, 1996.

McKERSIE, B. D.; STINSON, R. H. Effect of dehydration on leakage and membrane structure in Lotus corniculatus L. seeds. Plant Physiology, Bethesda, v.66, n.2, p.316-320, 1980.

NAKAGAWA, J. Testes de vigor baseados no desempenho das plântulas. In: KRZYZANOWSKI, F.; VIEIRA, R.D.; FRANÇA-NETO, J.B. (Ed.). Vigor de sementes: conceitos e testes. Londrina: ABRATES, 1999. cap.2, p.2-24.

NOODÉN, L.D.; BLAKLEY, K.A.; GRZYBOWSKI, J.M. Control of seed coat thickness and permeability in soybean. Plant Physiology, Lancaster, v.79, p.543-545. 1985.

PANOBIANCO, M.; VIEIRA, R.D.; KRZYZANOWSKI, F.C.; FRANÇA NETO, J.B. Electrical conductivity of soybean seed and correlation with seed coat lignin content. Seed Science and Technology, Zurich, v.27, n.3, p.945949, 1999.

ROBERTS, E.H. Loss of seed viability: chromosomal and genetic aspects. Seed Science and Technology, Zurich, v.1, n.3, p.515-527, 1973.

SEFA-DEDEH, S.; STANLEY ,D.W. The relationship of microstructure of cowpeas to water absorption and dehulling properties. Cereal Chemistry, St. Paul, v.56, p.379-386. 1979.

SIMON, E.W.; RAJA HARUN, R.M. Leakage during seed imbibition. Journal of Experimental Botany, Oxford, v.23, n.77, p. 1076-1085, 1972.

SWANSON, B.G.; HUGHES, J.S.; RASMUSSEN, H. Seed microstructure: review of water imbibition in legumes. Food Microstructure, Chicago, v.4, p.115-124. 1985.

TAVARES, D.Q.; MIRANDA, M.A.C.; UMINO, C.Y.; DIAS, G.M. Características estruturais do tegumento de sementes de linhagens de soja permeável e impermeável. Revista Brasileira de Botânica, São Paulo, v.10, p.147153, 1987.

VAN SOEST, P.J., WINE, R.H. Determination of lignin and cellulose in acid-detergent fiber with permanganate. Journal of the Association of Official Agricultural Chemists, Washington, v.51, p.780-5, 1968.

VIEIRA, R.D.; KRZYZANOWSKI, F.C. Teste de condutividade elétrica. In: KRZYZANOWSKI, F.C.; 
VIEIRA, R.D.; FRANÇA NETO, J. de B. (Ed.) Vigor de sementes: conceitos e testes. Londrina: ABRATES, 1999. Cap. 4, p. 1-26.

VIEIRA, R.D.; SEDIYAMA, T.; SILVA, R.F.; SEDIYAMA, C.S.; THIÉBAUT, J.T. Efeito do retardamento da colheita sobre a qualidade de sementes de soja cv. "UFV-2". Revista Brasileira de Sementes, Brasília, DF, v.4, n.2, p.9-22, 1982.
WOODSTOCK, L.W. Physiological and biochemical tests for seed vigor. Seed Science and Technology, Zurich, v.1, n.1, p.127-157, 1973.

YAKLICH, R.W.; WERGIN W. P.; ERBE, E.F. Use of low temperature scanning electron microscopy to observe frozen hydrated seed tissues of Glycine max. Seed Science Research, Wallingford, v.4, p.347-353, 1994. 